\title{
Unusual through-thickness variations of microstructure and texture in heavily rolled and annealed $\mathrm{Al}-0.3 \% \mathrm{Cu}$
}

Shuai, L.F.; Huang, T.L.; Wu, G.L.; Winther, G.; Huang, X.; Mishin, O.V.

Published in:

Materials Characterization

Link to article, DOI:

10.1016/j.matchar.2020.110173

Publication date:

2020

Document Version

Peer reviewed version

Link back to DTU Orbit

Citation (APA):

Shuai, L. F., Huang, T. L., Wu, G. L., Winther, G., Huang, X., \& Mishin, O. V. (2020). Unusual through-thickness variations of microstructure and texture in heavily rolled and annealed $\mathrm{Al}-0.3 \% \mathrm{Cu}$. Materials Characterization, 162, [110173]. https://doi.org/10.1016/j.matchar.2020.110173

\section{General rights}

Copyright and moral rights for the publications made accessible in the public portal are retained by the authors and/or other copyright owners and it is a condition of accessing publications that users recognise and abide by the legal requirements associated with these rights.

- Users may download and print one copy of any publication from the public portal for the purpose of private study or research.

- You may not further distribute the material or use it for any profit-making activity or commercial gain

- You may freely distribute the URL identifying the publication in the public portal 


\title{
Unusual through-thickness variations of microstructure and texture in heavily rolled and annealed $\mathrm{Al}-0.3 \% \mathrm{Cu}$
}

\author{
L.F. Shuai ${ }^{\text {a,b,c }}$, T.L. Huang a,b,*, G.L. Wu ${ }^{\text {a,b }}$, G. Winther ${ }^{c}$, X. Huang ${ }^{\text {a,b,c }}$, O.V. Mishin ${ }^{\text {ac, }, * *}$ \\ a International Joint Laboratory for Light Alloys (MOE), College of Materials Science and \\ Engineering, Chongqing University, Chongqing 400045, China
}

b Shenyang National Laboratory for Materials Science, Chongqing University, Chongqing 400044, China

${ }^{c}$ Department of Mechanical Engineering, Technical University of Denmark, 2800 Kgs. Lyngby, Denmark

${ }^{*}$ Corresponding author. International Joint Laboratory for Light Alloys (MOE), College of Materials Science and Engineering, Chongqing University, Chongqing, 400045, China

** Corresponding author. Department of Mechanical Engineering, Technical University of Denmark, 2800 Kgs. Lyngby, Denmark

E-mail addresses: huangtl@cqu.edu.cn (T.L. Huang), olmi@mek.dtu.dk (O.V. Mishin).

\begin{abstract}
The evolution of microstructure and texture has been investigated in coarse-grained $\mathrm{Al}-0.3 \% \mathrm{Cu}$ subjected to $98 \%$ cold rolling and subsequent annealing for $1 \mathrm{~h}$ at temperatures up to $300{ }^{\circ} \mathrm{C}$. In the rolled material the distribution of crystallographic orientations is found to be highly non-uniform through the sample thickness, with the center layer being strongly dominated by the Bs component, whereas no single texture component dominates in the subsurface. The rolled microstructure contains lamellar structures and a large number of shear bands in all layers. The shear bands promote
\end{abstract}


nucleation of Goss-oriented and other grains in the center layer. Most grains nucleated in the subsurface have random orientations. In the fully recrystallized microstructure obtained after annealing at $225^{\circ} \mathrm{C}$ for $1 \mathrm{~h}$, a strong Goss texture is formed in the center layer, while random orientations constitute the greatest area fraction of all orientations in the subsurface. Grain growth taking place after complete recrystallization at $250{ }^{\circ} \mathrm{C}$ and $300{ }^{\circ} \mathrm{C}$ leads to unusually high fractions of the Goss texture and high fractions of low angle boundaries in the center layer. In the subsurface layers, grain growth results in increased fractions of random orientations, and consequently most grain boundaries in these layers are high angle boundaries. The sample annealed at $300{ }^{\circ} \mathrm{C}$ for $1 \mathrm{~h}$ exhibits a pronounced sandwich-type structure, with a Goss-oriented band in the center layer enclosed by subsurface layers containing coarser grains of many different orientations.

Keywords: aluminum alloys; cold rolling; annealing; Goss texture; microstructure heterogeneity; scanning electron microscopy

\section{Introduction}

Thermo-mechanical processing of metallic materials frequently results in sample-scale heterogeneities of the microstructure and crystallographic texture [1-4]. This is especially true for materials processed by rolling, where through-thickness gradients of the microstructure and texture are usually observed [5-14]. Both friction and roll gap geometry control the distribution of strain through the sample thickness, which can induce different through-thickness gradients in rolled materials. The most commonly reported sample-scale heterogeneity after conventional rolling is associated with an increased shear strain near the surface of rolled products. In face centered cubic materials, this strain results in a so-called shear texture dominated by the $\{001\}\langle 110\rangle$ component, 
whereas the center layer typically demonstrates strong texture components characteristic of plane strain compression, i.e. Brass (Bs) $\{110\}\langle 112\rangle$, S $\{123\}\langle 634\rangle$ and Copper (Cu) $\{112\}\langle 111\rangle$ components. Upon annealing such deformation-induced gradients inevitably lead to heterogeneities in the recrystallized microstructure and texture [13,14], which can affect the mechanical behavior of the product.

The development of texture gradients during conventional rolling as a function of roll gap geometry and friction coefficient has been described in a large number of publications, e.g. [5-11]. Other texture gradients can develop during asymmetric rolling [14-16] or due to heterogeneities present in the material before rolling, such as variations in the initial texture or/and initial grain size. In particular, it is known that the evolution of microstructure and texture during rolling of samples with a coarse initial grain size can be substantially different from those in initially fine-grained samples, leading also to significant differences in their annealing textures $[17,18]$.

In several recent studies of a heavily cold-rolled $\mathrm{Al}-0.3 \% \mathrm{Cu}$ alloy with a large initial grain size, an unusually strong Bs texture was observed in the center layer of the deformed material, while a very strong Goss texture developed in this layer during recrystallization and grain growth [19-21]. Since rather atypical microstructures and textures were observed in the center layer of this alloy, it is of interest to investigate whether this material also contains unusual through-thickness gradients. In the present work, an investigation of through-thickness variations of the microstructure and texture is conducted for the $\mathrm{Al}-0.3 \% \mathrm{Cu}$ alloy cold-rolled to $98 \%$ and annealed isochronally at different temperatures. 


\section{Experimental}

An $\mathrm{Al}-0.3 \% \mathrm{Cu}$ alloy with $1.5-2 \mathrm{~mm}$ large grains in the as-cast condition was forged at $200{ }^{\circ} \mathrm{C}$ to obtain a $50 \mathrm{~mm}$ thick plate suitable for cold rolling. The texture of this forged sample contained an increased intensity of orientations near the Goss component [19]. This sample was $98 \%$ cold-rolled unidirectionally by 15 passes with no lubrication to a final thickness of $\sim 1 \mathrm{~mm}$ (von Mises strain $\left.\varepsilon_{\mathrm{VM}}=4.5\right)$. The $1 / \mathrm{h}$ ratio, where 1 is the chordal length of the contact between the rolls and the specimen, and $\mathrm{h}$ is the mean sample thickness [9], was maintained within the range 3 to 4 . The sample was then annealed in air at temperatures in the range $100-300{ }^{\circ} \mathrm{C}$.

For each condition, a section containing the rolling direction (RD) and the normal direction (ND) was polished mechanically and then electrochemically in a Struers A2 electrolyte at $-15{ }^{\circ} \mathrm{C}$. The polished sections were investigated using a Zeiss Supra 35 field emission gun scanning electron microscope (SEM) and a Zeiss AURIGA dual-beam SEM. Backscattered electron (BSE) images were taken to reveal second phase particles present in the microstructure. The microstructure and crystallographic texture were then investigated using electron backscatter diffraction (EBSD). EBSD data were collected at accelerating voltages of $15 \mathrm{kV}$ and $20 \mathrm{kV}$, applying a step size of 25-30 nm for investigations of the deformed microstructure and a step size of $0.5-2 \mu \mathrm{m}$ for studying grains in the partially and fully recrystallized conditions. For each sample, several orientation maps from different regions were collected to enable statistically sound data. Low angle boundaries (LABs) and high angle boundaries (HABs) were defined in these maps as those with misorientation angles $\theta=2-15^{\circ}$ and $\theta \geq 15^{\circ}$, respectively. Recrystallized grains were defined as regions greater than $5 \mu \mathrm{m}$ with internal misorientations less than $1^{\circ}$, at least partly surrounded by HABs [22]. 
Textures were studied through the sample thickness with a step size of either $4 \mu \mathrm{m}$ or $5 \mu \mathrm{m}$. Each through-thickness data set was divided into 3 subsets, corresponding to three layers of equal thickness: one center layer and two opposite subsurface layers. The data obtained from the two subsurface layers were averaged during quantitative analysis. Fractions of different texture components were calculated applying a $15^{\circ}$ deviation from the closest exact $\{\mathrm{hk} 1\}\langle\mathrm{uvw}\rangle$ orientation. In addition to the fractions of the Goss, Q $\{013\}\langle 231\rangle, \mathrm{Bs}, \mathrm{S}$ and $\mathrm{Cu}$ components analyzed in our previous publication [20], fractions of the shear (Sh) $\{001\}\langle 110\rangle$ and ND-rotated cube (CND) $\{001\}\langle 310\rangle$ were also calculated in the present experiment, as the latter components became prominent in the recrystallized subsurface layers. Vickers hardness was measured along the mid-thickness in the RD-ND section with a load of $500 \mathrm{gf}$ and a dwell time of $15 \mathrm{~s}$.

\section{Results}

\subsection{Cold-rolled material}

Figure 1 presents orientation distribution functions (ODFs) calculated from the EBSD data in four different locations of the sample, covering a total area of $\sim 3 \mathrm{~mm}^{2}$. It is obvious that the Bs component strongly dominates the crystallographic texture in the center layer (see Fig.1a). Analysis of the data indicates that in the center layer the area fraction of the Bs component $\left(f_{\mathrm{Bs}}\right)$ is $65 \%$, whereas area fractions of the $\mathrm{S}, \mathrm{Cu}$ and Goss $(\mathrm{G})$ components are $14 \%, 5 \%$ and $6 \%$, respectively (see Table 1). A very different rolling texture is observed in the subsurface (Fig.1b). Here the fractions of the Bs, $\mathrm{S}$ and $\mathrm{Cu}$ components are approximately $20-30 \%$ each, while the fraction of the G texture is only $3 \%$. The fraction of the $\{001\}\langle 110\rangle$ shear texture component in the subsurface is $<1 \%$. The $\{001\}\langle 110\rangle$ component is similarly weak very near the sample surface, as determined from the EBSD data 
collected in the rolling plane after only gentle electropolishing.

Examination of several regions in the rolled material reveals considerable local variations in the microstructure, which reflects the extremely large initial grain size. Example orientation maps in Fig.2 capture the key differences between the different layers of the deformed sample, namely the predominance of the Bs component in the center and a more uniform distribution of the three major rolling texture components in the subsurface. It is seen that each layer contains lamellar structures intersected by shear bands at approximately $20^{\circ}$ to $40^{\circ}$ to the RD (see Fig.2 and Fig.3). The average boundary spacing along the ND $(d \mathrm{ND})$ is slightly smaller in the center, $212 \mathrm{~nm}$, than in the subsurface, $242 \mathrm{~nm}$ (Table 1). Fine $\mathrm{Al}_{2} \mathrm{Cu}$ particles (seen as bright features in BSE images) are present along some boundaries in the microstructure, see Fig.3. The frequency of such particles is, however, rather small in all layers of the as-rolled sample.

Table 1 also presents average fractions of HABs $\left(f_{\mathrm{HAB}}\right)$ in the different layers. It is seen that in the strongly textured center layer $f_{\mathrm{HAB}}$ is rather small, $31 \%$. In the subsurface layer, the fraction of HABs is significantly larger, $62 \%$.

Table 1. Fractions of different texture components and parameters of the microstructure as measured using EBSD in the rolled material

\begin{tabular}{lcccccc}
\hline Layer & $f_{\mathrm{Bs}}(\%)$ & $f_{\mathrm{S}}(\%)$ & $f_{\mathrm{Cu}}(\%)$ & $f_{\mathrm{G}}(\%)$ & $d_{\mathrm{ND}}(\mathrm{nm})$ & $f_{\mathrm{HAB}}(\%)$ \\
\hline Center & 65 & 14 & 5 & 6 & 212 & 31 \\
Subsurface & 27 & 32 & 22 & 3 & 242 & 62 \\
\hline
\end{tabular}




\subsection{Annealed samples}

To select samples for microstructure and texture examinations, Vickers hardness was measured in a large number of samples annealed for $1 \mathrm{~h}$ in the temperature range $100-300{ }^{\circ} \mathrm{C}$. The results of these measurements are shown in Fig.4 along with the hardness of the as-rolled material. It is evident that the hardness decreases from $66 \mathrm{HV}$ in the as-rolled condition to $46 \mathrm{HV}$ after annealing at $150{ }^{\circ} \mathrm{C}$ and that the slope of the softening curve changes significantly between $150{ }^{\circ} \mathrm{C}$ and $200{ }^{\circ} \mathrm{C}$, followed by an almost constant hardness of $21-23 \mathrm{HV}$ between $200{ }^{\circ} \mathrm{C}$ and $300{ }^{\circ} \mathrm{C}$. The shape of this curve suggests that the softening at temperatures up to $150^{\circ} \mathrm{C}$ is mostly due to recovery and that recrystallization takes place at temperatures above $150{ }^{\circ} \mathrm{C}$. The same conclusion was also made by Huang et al. [21], who studied the influence of structural parameters in the center of the same sample on strength. Based on the softening curve, six samples were chosen for SEM characterizations.

Figure 5 shows the microstructure in the center of the sample annealed at $150{ }^{\circ} \mathrm{C}$ along with the microstructure of the as-rolled sample to facilitate comparison between these two conditions. It is obvious that the annealed microstructure is significantly coarser and contains a much higher frequency of $\mathrm{Al}_{2} \mathrm{Cu}$ particles than that in the rolled sample (cf. Fig.5a and Fig.5b). The particles precipitate along the lamellar boundaries, so that previous boundary locations decorated by the precipitates can be easily traced in the coarsened microstructure. The average boundary spacing along the ND is approximately $450 \mathrm{~nm}$ in the center layer and $480 \mathrm{~nm}$ in the subsurface. Despite the twofold increase in $d_{\mathrm{ND}}$ as compared to that in the as-rolled sample (see Table 1), the lamellar morphology is preserved in this annealed condition. No recrystallized grains were found in the areas examined. 
Coarsening of the deformed microstructure and precipitation also take place during annealing at $175^{\circ} \mathrm{C}$. However, the microstructure annealed at this temperature already contains recrystallized grains (see Fig.6 and Fig.7). While the average size $D_{\text {Rex }}$ of such grains is similar $(\sim 10 \mu \mathrm{m})$ in the center and subsurface layers, the fraction of the recrystallized microstructure $f_{\text {Rex }}$ is slightly different in these layers, $3 \%$ in the center and $8 \%$ in the subsurface (averaged over the two opposite layers). Recrystallization is seen to initiate in shear bands, where grains of Goss, Q and random orientations are found more frequently than grains of other orientations, and within horizontal bands with a large variety of orientations. Furthermore, it is found that very small recrystallized grains are typically particle-free, whereas comparatively large grains always contain arrays of particles aligned with lamellar boundaries that were present in the deformed microstructure before annealing (see Fig.7). This observation suggests that during annealing at $175^{\circ} \mathrm{C}$ nuclei first appear in particle-free regions and that further recrystallization occurs concurrently with precipitation.

After $1 \mathrm{~h}$ at $200{ }^{\circ} \mathrm{C}, f_{\text {Rex }}$ is already $67 \%$ and $71 \%$ in the center and subsurface layers, respectively (see Fig.8a and Fig.9a) and $D_{\text {Rex }}$ is $14-15 \mu \mathrm{m}$ (Fig.8b). The pronounced recrystallization results in significant changes in texture. The Bs orientation is no longer the strongest texture component in the center layer, and fractions of the Goss, Q and random orientations are all higher than those in the asdeformed condition and after annealing at $175^{\circ} \mathrm{C}$ (see Fig.10a). In the subsurface, the $\mathrm{Bs}, \mathrm{S}$ and $\mathrm{Cu}$ components weaken during annealing at $200^{\circ} \mathrm{C}$, while fractions of the other texture components increase (Fig.10b).

At temperatures in the range $225-300{ }^{\circ} \mathrm{C}$ the microstructure is fully recrystallized (see Fig.8a and Fig.9b,c). The increase in the annealing temperature from $225^{\circ} \mathrm{C}$ or $250{ }^{\circ} \mathrm{C}$ results in mostly 
quantitative changes in the microstructure, such as an increase in the size of recrystallized grains in the sample annealed at $250{ }^{\circ} \mathrm{C}$ (Fig.9b) and a greater area fraction of the Goss texture in the center layer, where it reaches $64 \%$ (Fig.10a). The difference between the samples annealed at either $250{ }^{\circ} \mathrm{C}$ or $300{ }^{\circ} \mathrm{C}$ is more remarkable. Firstly, the average grain size $D_{\text {Rex }}$ in the subsurface of the sample annealed at $300^{\circ} \mathrm{C}$ is increased by a factor of almost 3 as compared to that in the sample annealed at $250{ }^{\circ} \mathrm{C}$ (Fig. $8 \mathrm{~b}$ ). Whereas the average $D_{\text {Rex }}$ in the subsurface of the sample annealed at $300{ }^{\circ} \mathrm{C}$ is $\sim 60$ $\mu \mathrm{m}$, a number of subsurface grains in this sample even reach a size of $300 \mu \mathrm{m}$. Such large grains are not observed after annealing at $250^{\circ} \mathrm{C}$ (cf. Fig.9b and Fig.9c). Secondly, there are significant differences in the spatial distribution of different texture components between these two samples. In contrast to the sample annealed at $250{ }^{\circ} \mathrm{C}$, where central Goss-oriented grains are frequently interspersed with grains of other orientations, there are very few non-Goss grains near the midthickness of the sample annealed at $300{ }^{\circ} \mathrm{C}$. Moreover, subsurface grains penetrate into the center layer of the latter sample, so that the fraction of the Goss texture here is even somewhat lower than that after annealing at $250{ }^{\circ} \mathrm{C}$ (see Fig.10a). In fact, in the sample annealed at $300{ }^{\circ} \mathrm{C}$, the Goss component is confined to a 200-300 $\mu \mathrm{m}$ wide band in the center layer. The subsurface grains in this sample are characterized by a higher fraction of random orientations and a lower fraction of the Gosstexture than those in the sample annealed at $250{ }^{\circ} \mathrm{C}$. The area fractions of the shear, $\mathrm{Q}$ and CND components in the subsurface of the $300{ }^{\circ} \mathrm{C}$ sample are also significant, $12 \%$ to $17 \%$ each. Thus, the sample annealed at $300{ }^{\circ} \mathrm{C}$ exhibits a very pronounced sandwich-type structure, with the Gossdominated central band and two subsurface layers containing grains of mostly random, shear, Q and CND orientations (Fig.9c and Fig.10). The grain boundary populations are also very different in the 
different layers of this sample. The majority of all boundaries in the center layer are LABs, whereas HABs dominate in the subsurface (Fig.9c).

\section{Discussion}

The material studied in the present work demonstrates rather unusual through-thickness variations in the cold-rolled and annealed conditions, clearly different from those described in Refs.[5-14]. The center layer of our deformed material is characterized by a very high fraction of the Bs component, which is replaced by an exceptionally strong Goss texture in the samples annealed at $250{ }^{\circ} \mathrm{C}$ and $300{ }^{\circ} \mathrm{C}$ for $1 \mathrm{~h}$. On the other hand, the deformation texture in the subsurface contains well-developed Bs, S and Cu components and no significant shear texture. In these subsurface layers, high fractions of random orientations are found after recrystallization and grain growth. The development of these unusual through-thickness heterogeneities during rolling and then annealing is considered in the following.

\subsection{Through-thickness heterogeneity of the rolled material}

In our previous paper [20], the dominance of the Bs component in the center layer of a $95 \%$ rolled Al- $0.3 \% \mathrm{Cu}$ sample has been attributed to combined effects of the initial texture (increased intensities of near-Goss orientations) and the large initial grain size. The initial texture is known to have a significant effect on the final rolling texture. In particular, as shown for pure aluminum [23], an initial Goss texture promotes a strong Bs texture during heavy rolling. The large initial grain size also makes the material prone to shear banding [17,18], which can further enhance the Goss texture with a subsequent rotation towards the Bs orientation during continued rolling to high strains [24]. In the extreme case, a very large grain size may even result in plastic deformation by predominantly single 
slip, at least up to moderate strains. In such a case, for $\sigma_{\mathrm{RD}}=-\sigma_{\mathrm{ND}}$ and lattice rotations computed according to [25], only the exact Goss orientation is stable, while all grain orientations, including those slightly deviating from the exact Goss orientation, will rotate towards Bs [26]. In general, a starting texture composed of $80 \%$ random orientations and $20 \%$ near-Goss orientations would evolve by single slip into a texture with $f_{\mathrm{Bs}}=92 \%$ and $f_{\mathrm{G}}=6 \%$ after $98 \%$ rolling. It should of course be noted that single slip conditions induce significant strain incompatibilities not accounted for in the simulations and that flattening of the grains at high rolling reductions implies relaxation of only some shear components. The real deformation conditions are obviously more complex due to shear banding taking place during heavy rolling. Therefore, in a real texture of any coarse-grained material the final texture is expected to be significantly weaker than the one simulated based only on single slip. It is thus possible that a number of factors, i.e. the combination of the specific initial texture and very coarse grains promoting single slip and intense shear banding, all contribute to the dominant Bs texture observed in the center layer. They all agree with the texture change between the $95 \%$ rolled sample and the present sample rolled to $98 \%$, where the fraction of the Bs component in the center layer increases from $51 \%$ to $65 \%$, while the fraction of the Goss component decreases from $11 \%$ to 6\% (see Ref.[20] and Table 1).

The different texture in the subsurface layer can be a result of a high frictional strain imposed by rolling without lubrication, i.e. RD-ND shear. This shear normally induces a strong $\{001\}\langle 110\rangle$ texture component, which is, however, not observed in the present material. In line with the single slip simulations for the center layer, analogous simulations with addition of a shear component of 0.4 of the rolling strain predict a dominant $\mathrm{S}$ component with $f_{\mathrm{S}}=70 \%$. This result is qualitatively 
consistent with the observed difference between the two layers, again suggesting that the role of the large initial grain size may indeed be important.

The significant differences in the rolling texture govern the spatial distribution of orientations and hence boundary populations in the different layers, where the fraction of HABs in the subsurface is higher due to the more balanced proportion of the $\mathrm{Bs}, \mathrm{S}$ and $\mathrm{Cu}$ components (see Table 1). These HABs are likely to migrate during dynamic recovery, which can explain the larger $d_{\mathrm{ND}}$ spacing seen in the subsurface as compared to that in the center (Table 1).

\subsection{Nucleation of recrystallized grains}

Recrystallization in the $98 \%$ rolled sample initially takes place at shear bands and in the horizontal bands with different orientations, as was also the case with the $95 \%$ rolled sample of the same material [20]. Shear bands are known to be preferential nucleation sites and the observed nucleation in these regions is not surprising. However, whereas nucleation at shear bands is usually considered to result in weak annealing textures $[17,18]$, the texture formed in the center layer of $\mathrm{Al}-$ $0.3 \% \mathrm{Cu}$ is rather strong even in the sample recrystallized at $225^{\circ} \mathrm{C}$ without appreciable grain growth (Fig.10a).

It has been previously shown that the Goss-oriented regions in heavily rolled $\mathrm{Al}-0.3 \% \mathrm{Cu}$ are characterized by a lower stored energy than regions of the Bs texture, which creates a driving force for Goss-oriented subgrains to grow into the matrix of the dominant Bs component [20]. The reason for the different stored energies in regions of the different texture components can be understood based on the analysis of their Taylor factors $M$. These factors are a measure of the plastic work, and can thus be related to the stored energy $[27,28]$. 
For heavily rolled microstructures, Taylor factors are usually calculated assuming plane strain compression with relaxed shear components and neglecting shear banding. Table 2 shows $M$ for several texture components in $\mathrm{Al}-0.3 \% \mathrm{Cu}$ calculated for plane strain compression with relaxed $\mathrm{RD}$ ND and TD-ND shear components, where TD is the transverse direction. The $\mathrm{Bs}, \mathrm{S}$ and $\mathrm{Cu}$ components, all of which vanish during annealing, are characterized by high Taylor factors $(M=3.3-$ 3.7) and hence presumably have higher stored energies. In contrast, Taylor factors for each of the components that become significant in the recrystallization texture are all considerably lower $(M<3)$ and so is the stored energy within these regions. It appears that the strength of the considered components in the annealing texture of the $\mathrm{Al}-0.3 \% \mathrm{Cu}$ sample is governed by the differences in their Taylor factors and energy stored during deformation.

Table 2. Taylor factors $M$ for several components identified in the rolling and annealing textures of $\mathrm{Al}-0.3 \% \mathrm{Cu}$

\begin{tabular}{ccccccc}
\hline Bs & S & Cu & G & Q & Sh & CND \\
$\{110\}\langle 112\rangle$ & $\{123\}\langle 634\rangle$ & $\{112\}\langle 111\rangle$ & $\{110\}\langle 001\rangle$ & $\{013\}\langle 231\rangle$ & $\{001\}\langle 110\rangle$ & $\{001\}\langle 310\rangle$ \\
\hline 3.27 & 3.39 & 3.67 & 2.45 & 2.71 & 2.45 & 2.45 \\
\hline
\end{tabular}

In general, grains nucleated prior to precipitation grow to a large size, presumably as these grains already reach a size large enough to overcome pinning before precipitation begins (see Fig.7). In the center layer, the Goss-oriented nuclei have a clear preference because they can nucleate both at shear bands, as initially proposed by Engler et al. [29], and within Bs/G bands where regions of the dominant Bs component are combined with Goss-oriented lamellae [20,30]. Though nucleation in 
shear bands also takes place in the subsurface layers, many more recrystallized grains here appear to nucleate in the horizontal bands with a large number of random and other orientations (see Fig.6). As a result, a weak recrystallization texture is produced in these layers (see Fig.10b).

\subsection{Evolution in the fully recrystallized samples}

Comparing the fully recrystallized conditions, it is evident that the only sample, where the microstructure and texture are not significantly affected by grain growth, is the sample annealed at $225^{\circ} \mathrm{C}$ for $1 \mathrm{~h}$. In contrast to this sample, microstructures annealed at $250{ }^{\circ} \mathrm{C}$ and $300{ }^{\circ} \mathrm{C}$ appear to have experienced substantial grain growth after complete recrystallization. It can therefore be concluded that the unusually strong Goss texture observed in the center of the latter samples is obtained when Goss-oriented grains grow at the expense of other recrystallized grains. During this process, growing Goss-oriented grains form low energy LABs with grains of similar orientations, which enables a more efficient reduction in the overall grain boundary energy in this layer (see Fig.9). A similar texture strengthening during grain growth does not occur in the subsurface layers since there is no single dominant orientation in their recrystallization texture. In these layers, grain growth primarily results in increased fractions of random orientations (Fig.10b).

The changes in texture and in the spatial distribution of grains with different orientations greatly affect the proportion of LABs and HABs in the recrystallized conditions. Texture strengthening during grain growth typically results in increased fractions of LABs $\left(f_{\mathrm{LAB}}\right)$ [31], as is also seen for the center layer of the samples annealed at either $225^{\circ} \mathrm{C}$ or $250{ }^{\circ} \mathrm{C}$. In these two samples, $f_{\mathrm{LAB}}$ increases from $26 \%$ to $36 \%$ (Fig. 11 ) as the Goss texture in the center strengthens from $f_{\mathrm{G}}=39 \%$ to $f_{\mathrm{G}}=64 \%$. Interestingly, $f_{\mathrm{LAB}}$ in the center layer increases even more, up to $66 \%$ (see Fig.11), as the annealing 
temperature changes from $250{ }^{\circ} \mathrm{C}$ to $300^{\circ} \mathrm{C}$ though there is no simultaneous increase in the fraction of the Goss texture. Obviously, the large difference in $f_{\mathrm{LAB}}$ in the center layer of the two samples annealed at either $250{ }^{\circ} \mathrm{C}$ or $300{ }^{\circ} \mathrm{C}$ reflect differences in the spatial distribution of orientations. In the center of the sample annealed at $250{ }^{\circ} \mathrm{C}$, the Goss grains are interspersed with grains of other orientations, which results in many HABs. Therefore, $f_{\mathrm{LAB}}$ is only $36 \%$ in this sample. In the sample annealed at $300{ }^{\circ} \mathrm{C}$, the spatial distribution of orientations is different. In the center of this sample, the Goss-oriented grains form one extended Goss band, where the vast majority of boundaries are LABs. HABs in this center layer are mostly observed on the periphery of the central Goss band, so that their fraction is significantly smaller than $f_{\mathrm{LAB}}$.

Considering the subsurface layers, there is only a minor increase in the LAB fraction with increasing annealing temperature, and $f_{\mathrm{LAB}}$ remains comparatively low, $22 \%$, even at $300{ }^{\circ} \mathrm{C}$ as a result of many different grain orientations present in these layers. During annealing at $300{ }^{\circ} \mathrm{C}$, the reduction in the grain boundary energy is achieved in these layers by grain growth both within the subsurface regions and into the center layer. Taking into account that the average size of the subsurface grains is larger than that of the central grains (see Fig.8b), it is reasonable to expect that if annealing at $300{ }^{\circ} \mathrm{C}$ is continued beyond $1 \mathrm{~h}$, the Goss-dominated layer in the center would largely be consumed by grains growing from the opposite subsurface layers.

\section{Conclusions}

1. Heavy rolling of an initially coarse-grained $\mathrm{Al}-0.3 \% \mathrm{Cu}$ sample results in a highly non-uniform distribution of crystallographic orientations through the sample thickness. The center layer is strongly dominated by the Bs component, while a more balanced proportion of the Bs, S and 
$\mathrm{Cu}$ components is found in the subsurface layers. These differences in the deformation texture lead to very different boundary populations in the different layers, where the fraction of HABs after $98 \%$ rolling is $31 \%$ in the center and $62 \%$ in the subsurface. Each layer contains lamellar structures intersected by a large number of shear bands. This type of microstructure and texture are retained at temperatures below $175^{\circ} \mathrm{C}$ when only recovery accompanied by structural coarsening and precipitation take place.

2. Recrystallization occurs during annealing for $1 \mathrm{~h}$ at a temperature of $175^{\circ} \mathrm{C}$ and above. As is evident from microstructural observations at an early stage of recrystallization (in the sample annealed at $175^{\circ} \mathrm{C}$ ), first recrystallized grains nucleate at shear bands and within horizontal bands with a large variety of orientations. The shear bands promote nucleation of Goss and other grains in the center layer. Nucleation in the subsurface predominantly generates grains of many different orientations.

3. The microstructure is fully recrystallized after annealing for $1 \mathrm{~h}$ at temperatures $\geq 225^{\circ} \mathrm{C}$. As the annealing temperature changes from $225^{\circ} \mathrm{C}$ to $250{ }^{\circ} \mathrm{C}$, the fraction of the Goss texture in the center increases from $39 \%$ up to $64 \%$ and the fraction of LABs increases from $26 \%$ to $36 \%$ as a result of grain growth taking place after complete recrystallization. In the subsurface layers of each recrystallized sample, random orientations are more frequent than orientations of any other component, and the majority of all grain boundaries are HABs.

4. The sample annealed at $300{ }^{\circ} \mathrm{C}$ exhibits a pronounced sandwich-type structure, with a continuous Goss-oriented band in the center layer and two subsurface layers containing grains of other orientations. The fraction of LABs is $66 \%$ in the center and $22 \%$ in the subsurface 
layers. The subsurface grains are coarser than those in the center and demonstrate the tendency to penetrate into the center layer.

Acknowledgements: The State Key Research and Development Program of MOST of China (2016YFB0700400) and NSFC of China (Nos. 51421001) are acknowledged for supporting this work. OVM thanks the support of the "111" Project (B16007) by the Ministry of Education and the State Administration of Foreign Experts Affairs of China. LS thanks the support of the European Research Council (ERC) under the European Union's Horizon 2020 research and innovation programme (ERC Advanced grant - M4D/grant agreement number 788567). Useful discussions with Professor A. Godfrey are gratefully acknowledged.

Declaration of conflict of interest: The authors declare that they have no conflict of interest associated with this publication.

\section{References}

[1] S. Panda, L.S. Toth, J.-J. Fundenberger, O. Perroud, J. Guyon, J. Zou, T. Grosdidier, Characteristic constitution model and microstructure of an $\mathrm{Al}-3.5 \mathrm{Cu}-1.5 \mathrm{Li}$ alloy subjected to thermal deformation, Mater. Charact. 123 (2017) 159-165.

[2] O.V. Mishin, Y. B. Zhang, A. Godfrey, The influence of multiscale heterogeneity on recrystallization in nickel processed by accumulative roll bonding, J. Mater. Sci. 52 (2017) $2730-2745$.

[3] O.V. Mishin, J.R. Bowen, Through-thickness variations of deformed and annealed microstructures in ECAE-processed copper, Metall. Mater. Trans. A 40 (2009) 1684-1692. 
[4] C.G. Figueroa, R. Schouwenaars, J. Cortés-Péreza, R. Petrov, L. Kestens, Ultrafine gradient microstructure induced by severe plastic deformation under sliding contact conditions in copper, Mater. Charact. 138 (2018) 263-273.

[5] W. Truszkowski, J. Krol, B. Major, Inhomogeneity of rolling texture in fec metals, Metall. Trans. A 11 (1980) 749-758.

[6] W. Truszkowski, J. Krol, B. Major, On penetration of shear texture into the rolled aluminum and copper, Metall. Trans. A 13 (1982) 665-669.

[7] S.E. Schoenfeld, R.J. Asaro, Through thickness texture gradients in rolled polycrystalline alloys, Int. J. Mech. Sci. 38 (1996) 661-683.

[8] C.-H. Choi, J.-W. Kwon, K.H. Oh, D.N. Lee, Analysis of deformation texture inhomogeneity and stability condition of shear components in f.c.c. metals, Acta Mater. 45 (1997) 997, 51195128.

[9] O.V. Mishin, B. Bay, D. Juul Jensen, Through-thickness texture gradients in cold-rolled aluminum, Metall. Mater. Trans. A 31 (2000) 1653-1662.

[10] O. Engler, M.-Y. Huh, C.N. Tomé, A study of through-thickness texture gradients in rolled sheets, Metall. Mater. Trans. A 31 (2000) 2299-2315.

[11] J.J. Sidor, Assessment of flow-line model in rolling texture simulations, Metals 9 (2019) 1098.

[12] O.V. Mishin, B. Bay, G. Winther, D. Juul Jensen, The effect of roll gap geometry on microstructure in cold-rolled aluminum, Acta Mater. 52 (2004) 5761-5770. 
[13] O.V. Mishin, A. Godfrey, Controlled annealing of sandwich-structured aluminum AA1050 for optimized combinations of strength and ductility, Mater. Sci. Eng. A735 (2018) 228-235.

[14] J.J. Nah, H.G. Kang, M.Y. Huh, O. Engler, Effect of strain states during cold rolling on the recrystallized grain size in an aluminum alloy, Scr. Mater. 58 (2008) 500-503.

[15] J. Sidor, A. Miroux, R. Petrov, L. Kestens, Microstructural and crystallographic aspects of conventional and asymmetric rolling processes, Acta Mater. 56 (2008) 2495-2507.

[16] S. Wronski, B. Ghilianu, T. Chauveau, B. Bacroix, Analysis of textures heterogeneity in cold and warm asymmetrically rolled aluminium, Mater. Charact. 62 (2011) 22-34.

[17] A.A. Ridha, W.B. Hutchinson, Recrystallisation mechanisms and the origin of cube texture in copper, Acta Metall. 30 (1982) 1929-1939.

[18] O. Engler, Influence of the initial grain size on the rolling and recrystallization textures in the alloy Al-1.8\% Cu, Textures Microstruct. 23 (1995) 61-86.

[19] X.R. Li, A. Wakeel, T.L. Huang, G.L. Wu, X. Huang, Recrystallization textures and microstructures of $\mathrm{Al}-0.3 \% \mathrm{Cu}$ alloy after deformation to high strains, IOP Conf. Ser. Mater. Sci. Eng. 89 (2015) 012032.

[20] L.F. Shuai, T.L. Huang, G.L. Wu, X. Huang, O.V. Mishin, Development of Goss texture in Al-0.3\%Cu annealed after heavy rolling, J. Alloys Compd. 749 (2018) 399-405.

[21] T. Huang, L. Shuai, A. Wakeel, G. Wu, N. Hansen, X. Huang, Strengthening mechanisms and Hall-Petch stress of ultrafine grained Al-0.3\%Cu, Acta Mater. 156 (2018) 369-378.

[22] G.L. Wu, D. Juul Jensen, Automatic determination of recrystallization parameters based on EBSD mapping, Mater. Charact. 59 (2008) 794-800. 
[23] J. Hirsch, W. Mao, K. Lücke, The modulation of rolling and recrystallization textures of aluminum by variation of the starting texture, Proc. Aluminium Technology 86, (1986) The Institute of Metals, London, 70.1-70.8.

[24] O. Engler, J. Hirsch, K. Lücke, Texture development in Al 1.8wt\% Cu depending on the precipitation state - I. Rolling textures, Acta Metall. Mater. 37 (1989) 2743-2753.

[25] U.F. Kocks, H. Chandra, Slip geometry in partially constrained deformation, Acta Metall. 30 (1982) 695-709.

[26] J. Hirsch, K. Lücke, Overview no. 76: Mechanism of deformation and development of rolling textures in polycrystalline f.c.c. metals-II. Simulation and interpretation of experiments on the basis of Taylor-type theories, Acta Metall. 36 (1988) 2883-2904.

[27] B. Hutchinson, Deformation microstructures and textures in steels, Philos. Trans. R. Soc. London, Ser. A 357 (1999) 1471-1485.

[28] J.J. Sidor, R.H. Petrov, L.A.I. Kestens, Modeling the crystallographic texture changes in aluminum alloys during recrystallization, Acta Mater 59 (2011) 5735-5748.

[29] O. Engler, J. Hirsch, K. Lücke, Texture development in Al-1.8 wt\% Cu depending on the precipitation state - II. Recrystallization textures, Acta Metall. Mater. 43 (1995) 121-138.

[30] J. Hjelen, R. Ørsund, E. Nes, On the origin of recrystallization textures in aluminium, Acta Metall. Mater. 39 (1991) 1377-1404.

[31] O.V. Mishin, G. Gottstein, Grain boundary ensembles due to grain growth in copper with strong recrystallization texture, Mater. Sci. Eng. A249 (1998) 71-78. 


\section{Figure captions}

Figure 1. ODF sections $\left(\varphi_{2}=0^{\circ}, 45^{\circ}\right.$ and $\left.65^{\circ}\right)$ representing texture in the center (a) and subsurface (b) layers of the $98 \%$ rolled $\mathrm{Al}-0.3 \% \mathrm{Cu}$ sample. Contour levels are 1, 3, 5, 10, 20, 30, $40 \times$ random . Positions of the $\mathrm{Bs}, \mathrm{S}, \mathrm{Cu}$ and $\mathrm{G}$ texture components are shown in (c).

Figure 2. Example orientation maps showing the microstructure in the center (a) and subsurface (b) of the $98 \%$ rolled $\mathrm{Al}-0.3 \% \mathrm{Cu}$ sample. Orientations that do not belong to any orientation listed in the color code are represented by different shadings of gray. LABs and HABs are shown as white and black lines, respectively. The RD is parallel to the scale bar. (For interpretation of the references to color in this figure legend, the reader is referred to the Web version of this article.)

Figure 3. BSE image from the center layer of the $98 \%$ rolled $\mathrm{Al}-0.3 \% \mathrm{Cu}$ sample showing a shear band intersecting lamellar structures. Small bright features along some lamellar boundaries are $\mathrm{Al}_{2} \mathrm{Cu}$ particles.

Figure 4. Evolution of Vickers hardness during annealing of the $98 \%$ rolled $\mathrm{Al}-0.3 \% \mathrm{Cu}$ sample for $1 \mathrm{~h}$ at different temperatures.

Figure 5. Effect of low-temperature annealing on the microstructure of the $98 \%$ rolled $\mathrm{Al}-0.3 \% \mathrm{Cu}$ sample: (a) as-rolled condition; (b) after annealing at $150{ }^{\circ} \mathrm{C}$ for $1 \mathrm{~h}$.

Figure 6. Orientation maps showing recrystallized grains in the sample annealed at $175^{\circ} \mathrm{C}$ for $1 \mathrm{~h}$ : (a) center; (b) subsurface. Orientations that do not belong to any orientation listed in the color code are represented by different shadings of gray. LABs and HABs are shown as white and black lines, respectively. The RD is parallel to the scale bar. (For interpretation of the references to color in this 
figure legend, the reader is referred to the Web version of this article.)

Figure 7. BSE images showing precipitates in partially recrystallized regions of the sample annealed at $175^{\circ} \mathrm{C}$ for $1 \mathrm{~h}$ : (a) center; (b) subsurface.

Figure 8. Changes in the area fraction (a) and average size (b) of recrystallized grains during annealing at different temperatures for $1 \mathrm{~h}$.

Figure 9. Orientation maps covering almost the entire thickness of the $\mathrm{Al}-0.3 \% \mathrm{Cu}$ sample annealed for $1 \mathrm{~h}$ at different temperatures: (a) $200{ }^{\circ} \mathrm{C}$ (a); (b) $250{ }^{\circ} \mathrm{C}$ and (c) $300{ }^{\circ} \mathrm{C}$. Orientations that do not belong to any orientation listed in the color code are represented by different shadings of gray. LABs and HABs are shown as white and black lines, respectively. The RD is parallel to the scale bar. (For interpretation of the references to color in this figure legend, the reader is referred to the Web version of this article.)

Figure 10. Fractions of different texture components in the as-rolled and annealed conditions: (a) center; (b) subsurface.

Figure 11. Fractions of LABs in the fully recrystallized samples. 

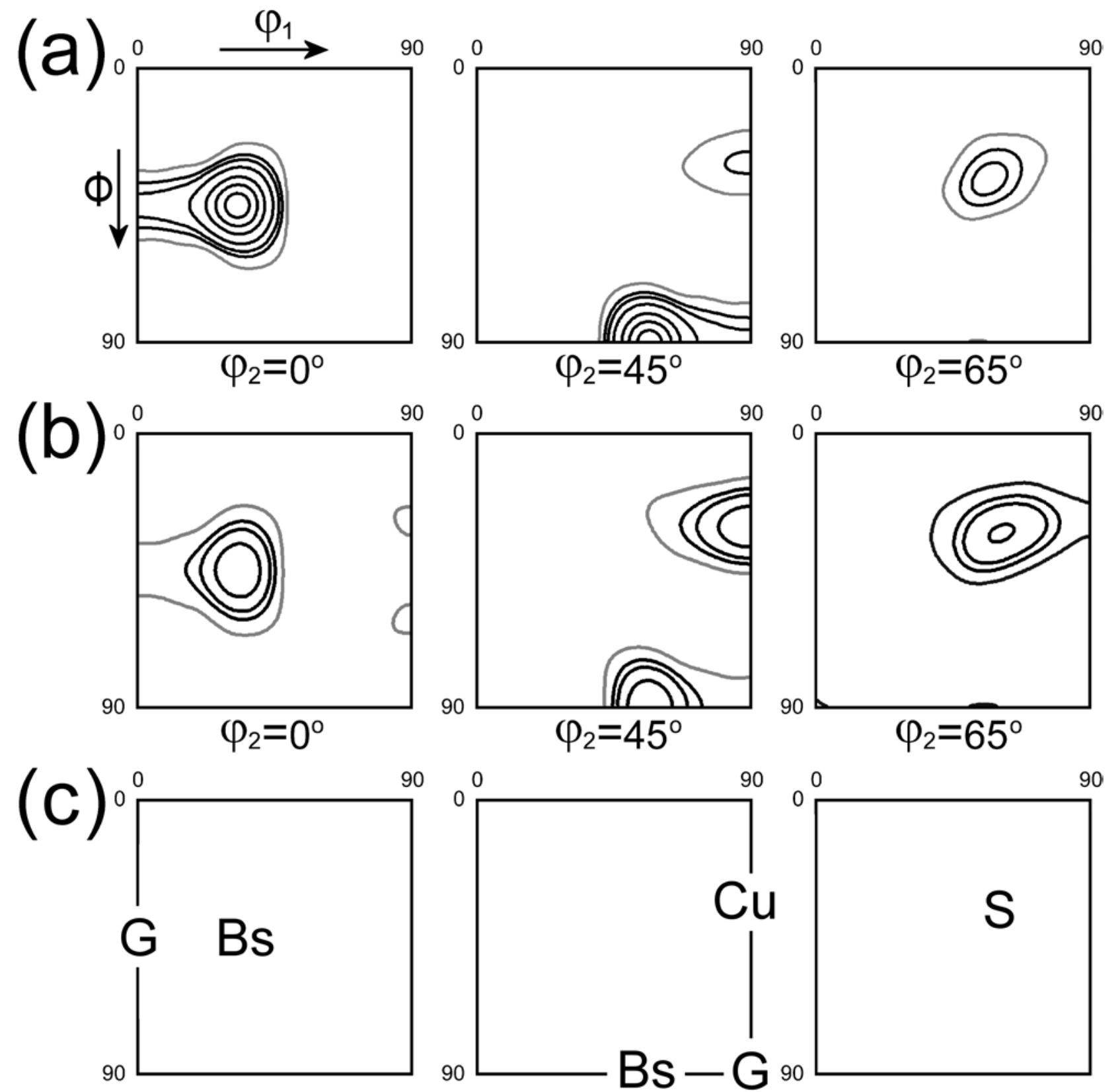
(a)

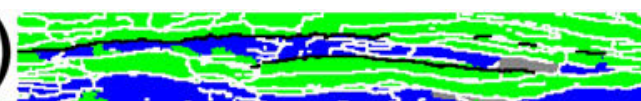
(a)

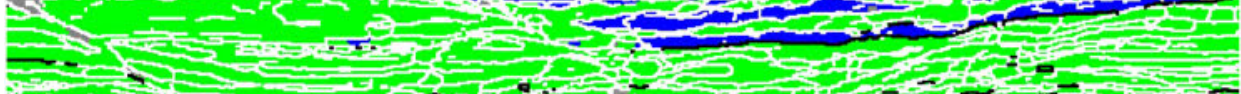

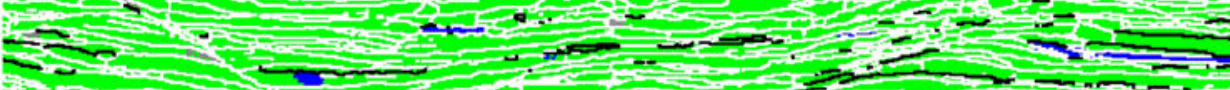

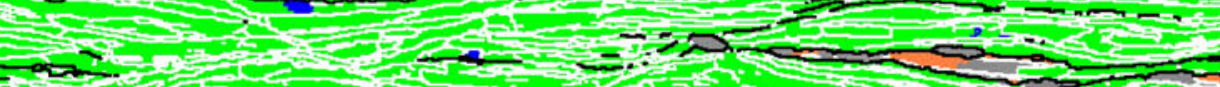

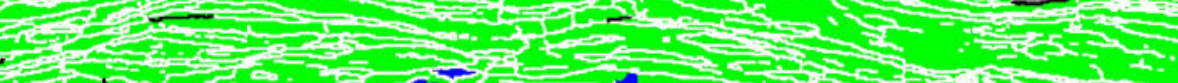

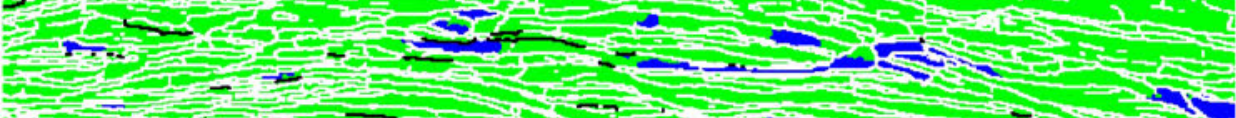

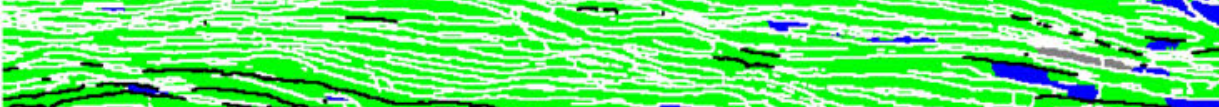

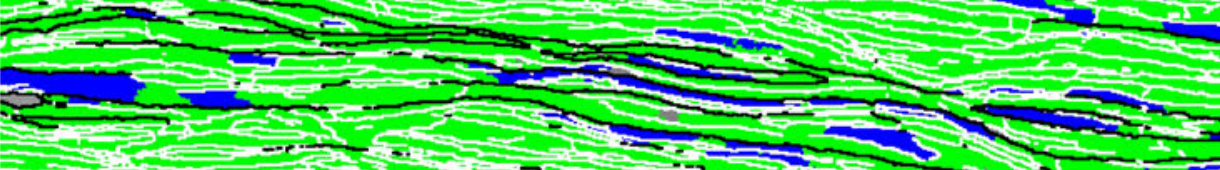

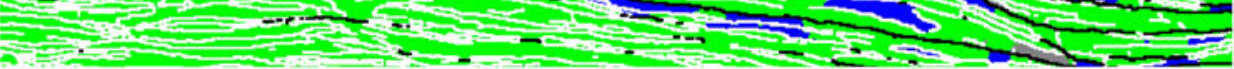
G
Q
Sh

CND

$\square$ Bs

(b)

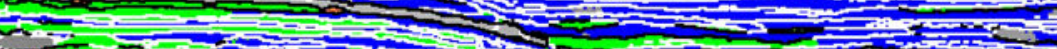

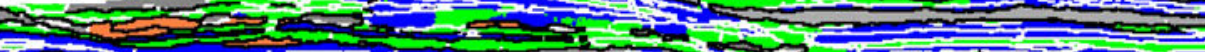

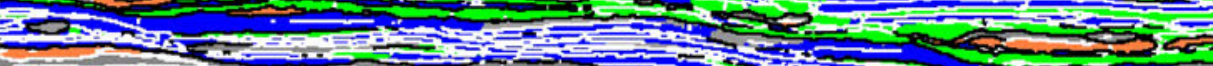

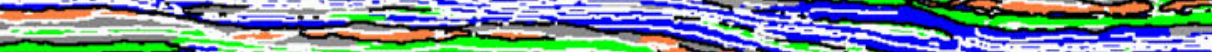

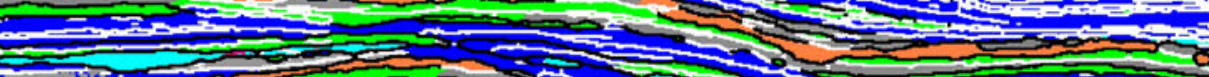

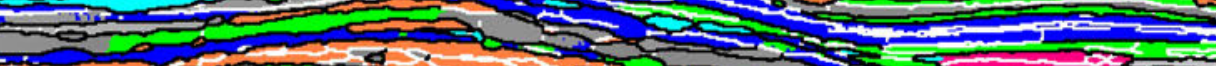

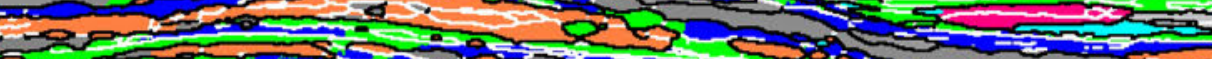

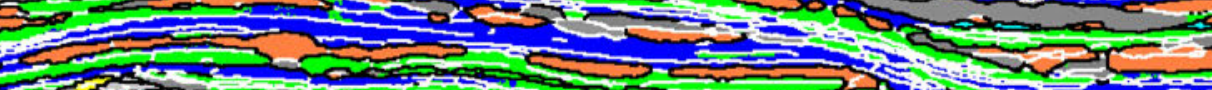

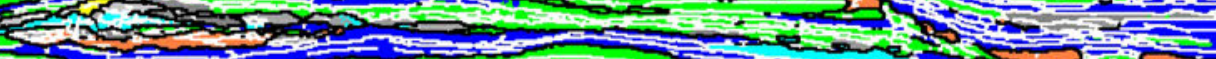

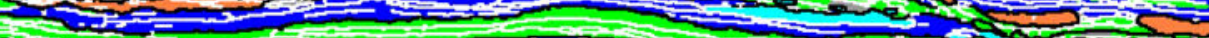

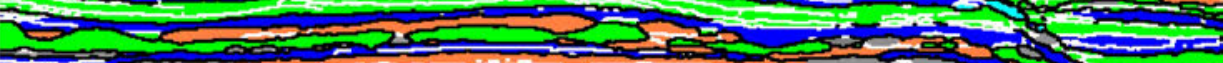

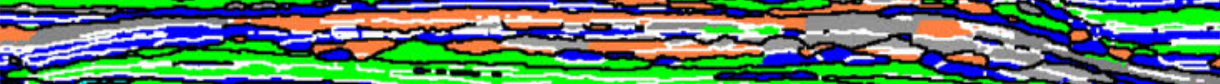
Sor.

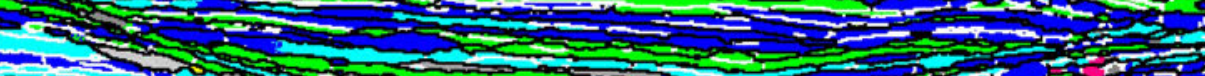

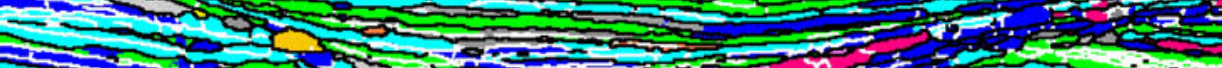

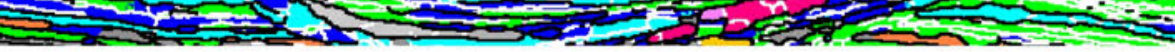
$\square$

$\square$ Sh $\square$ CND $\square$




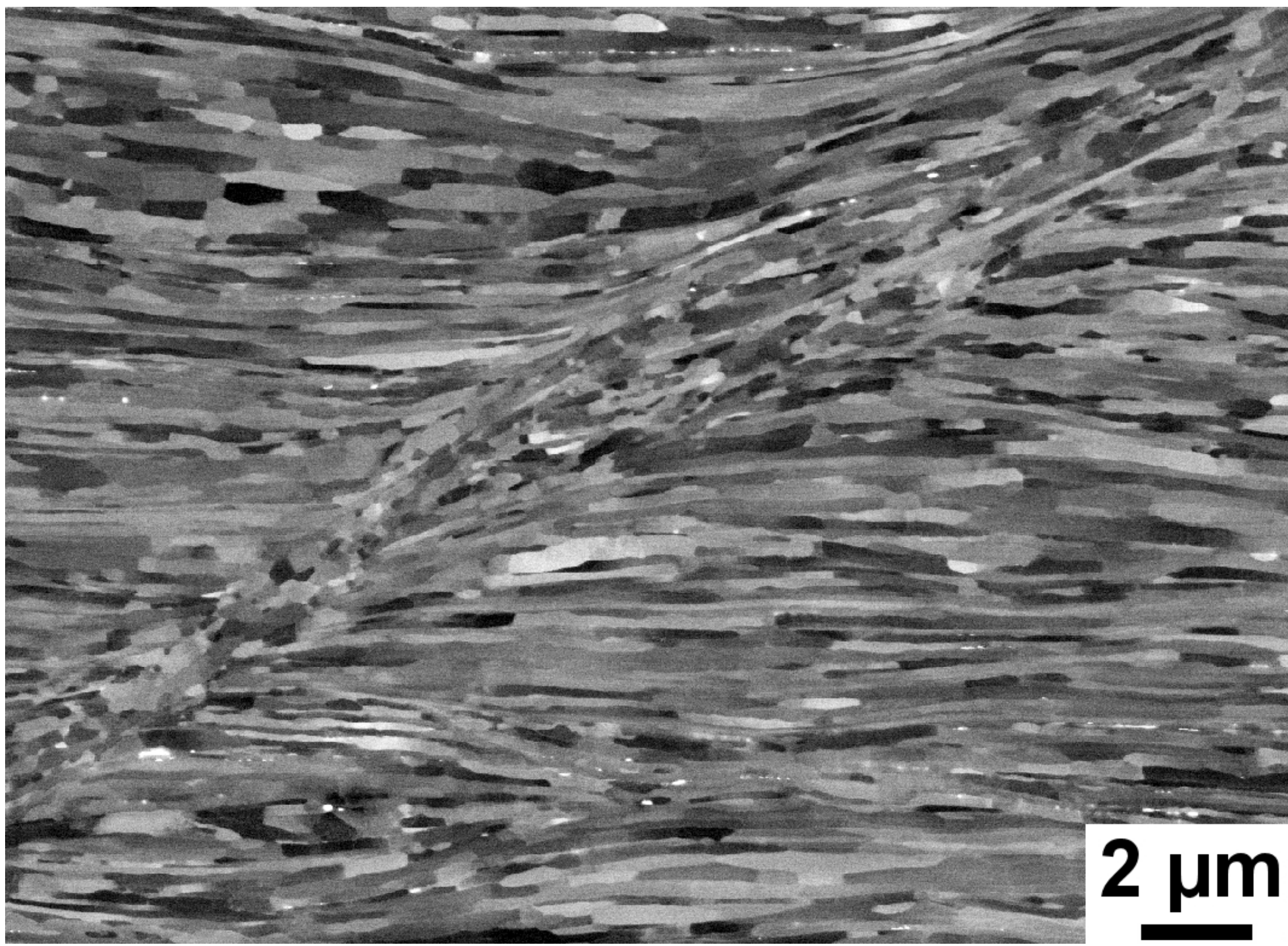




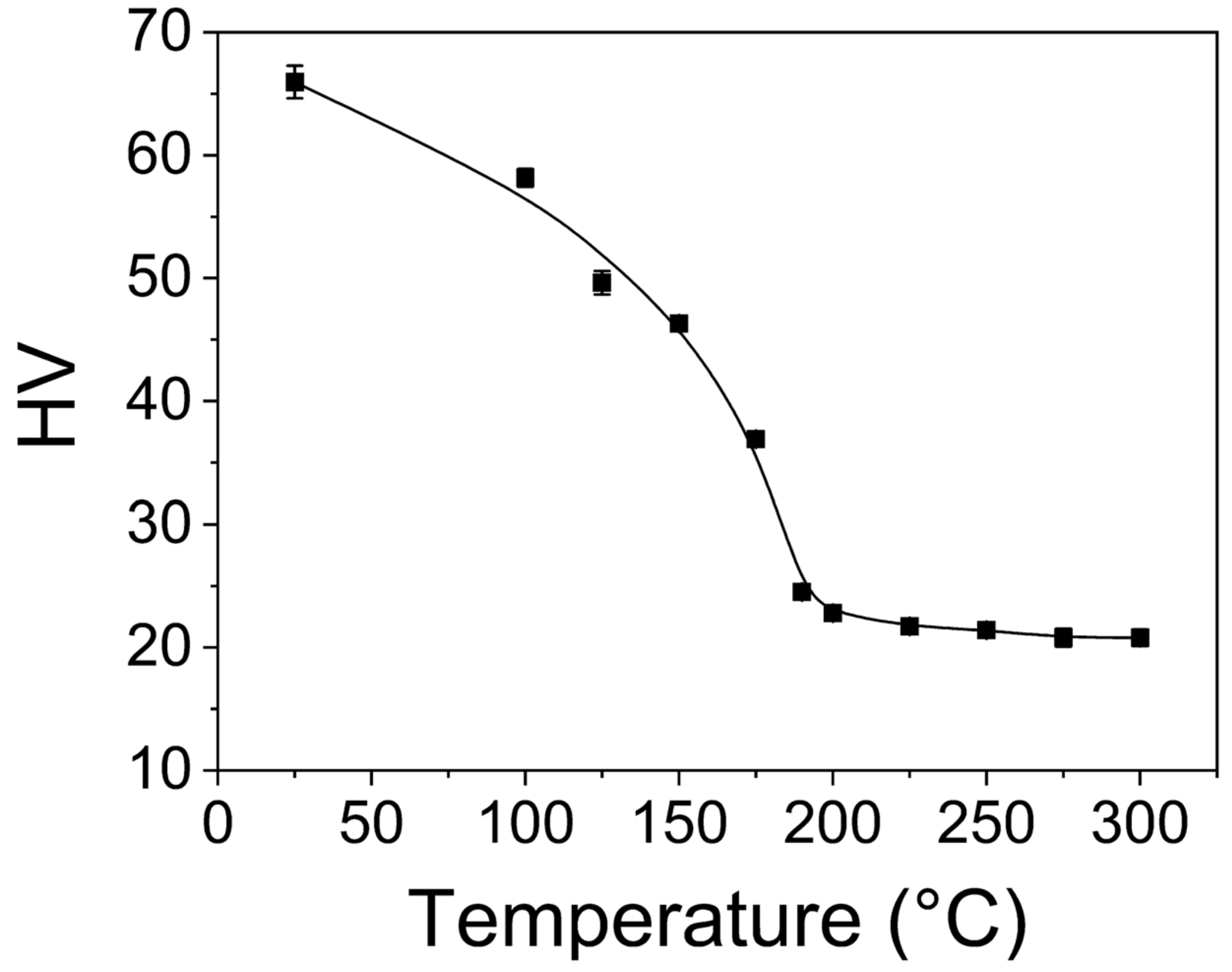



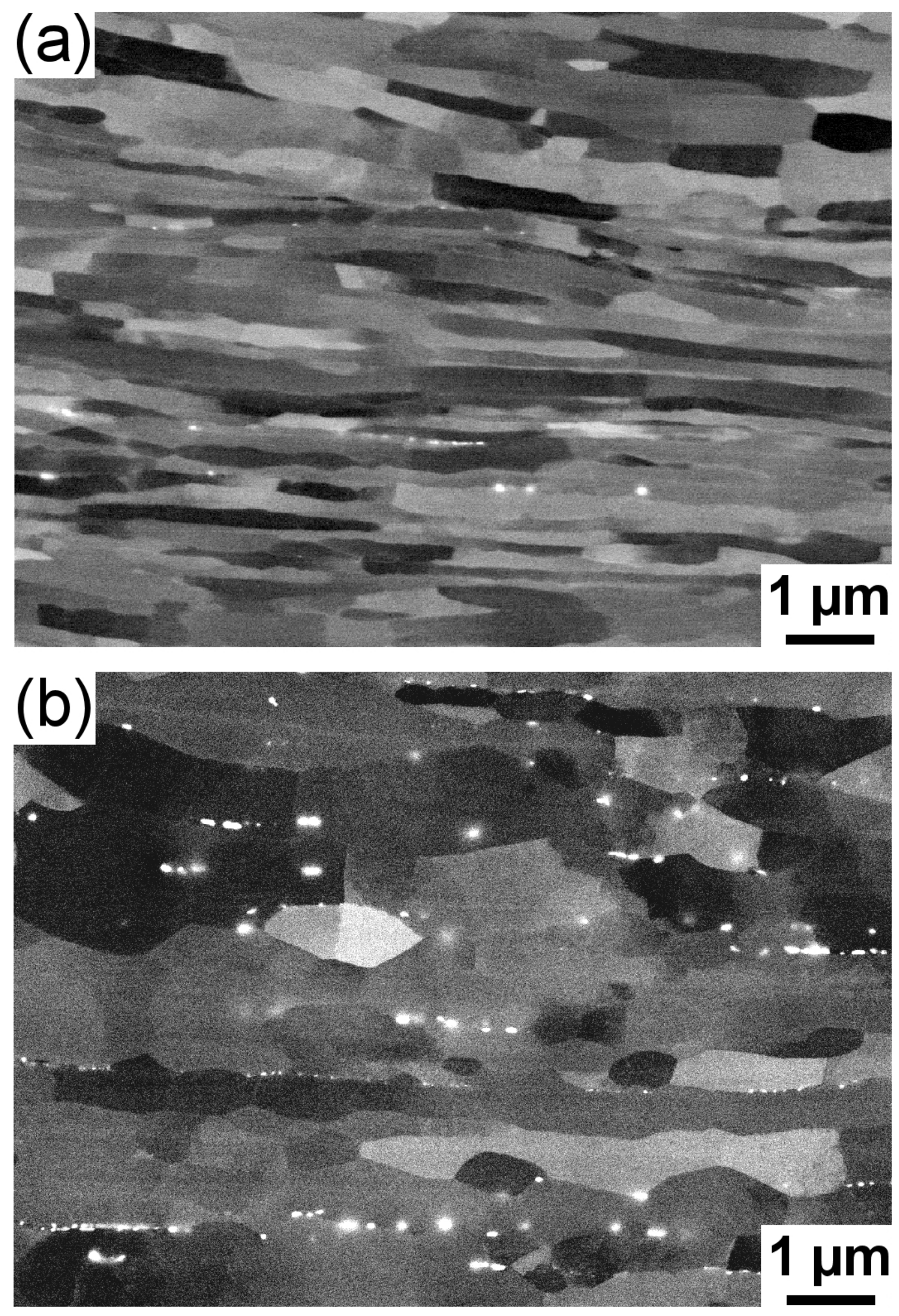
(a)

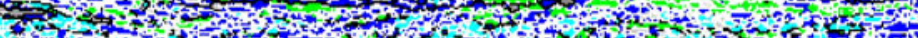

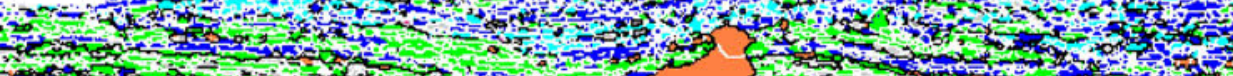

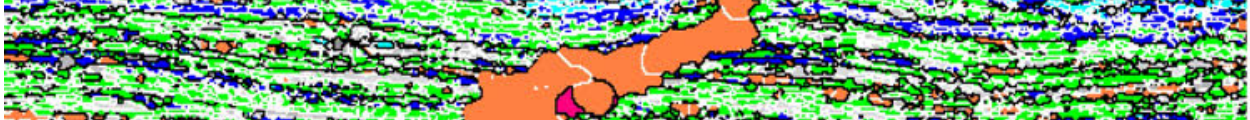

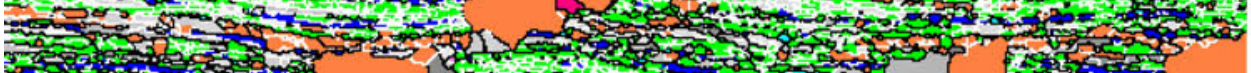

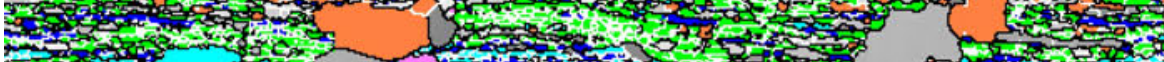

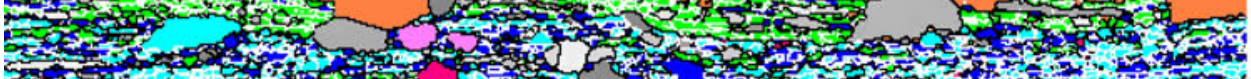

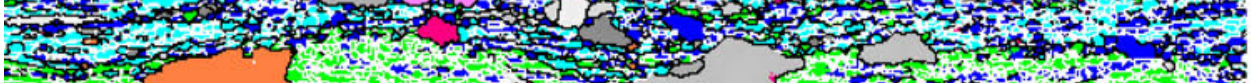
Niv Ln

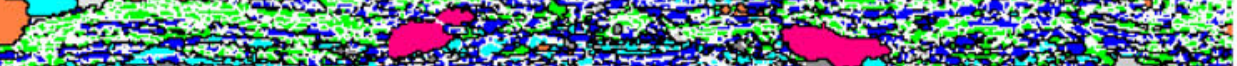

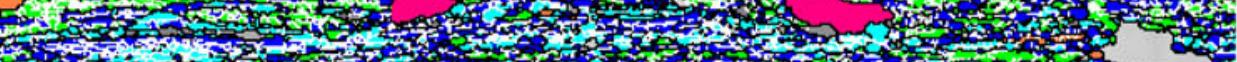

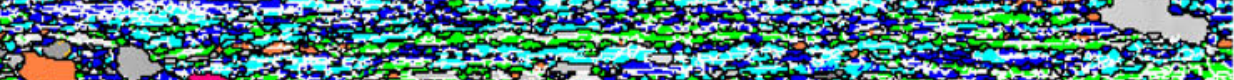

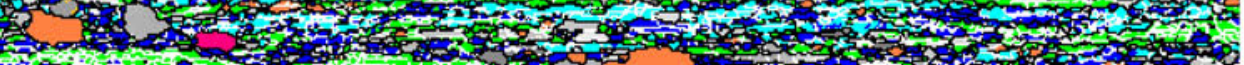

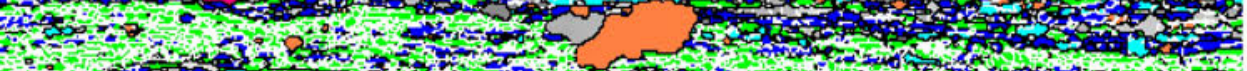

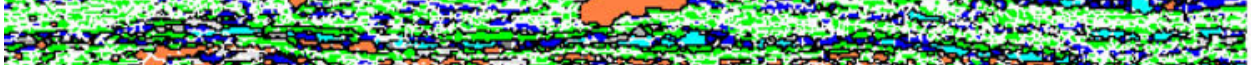

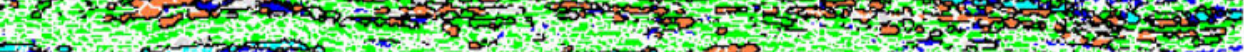

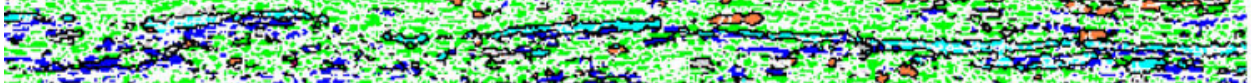

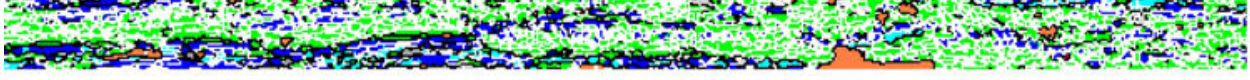

Q Sh
CND (b) 1.

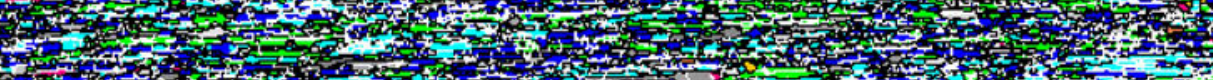

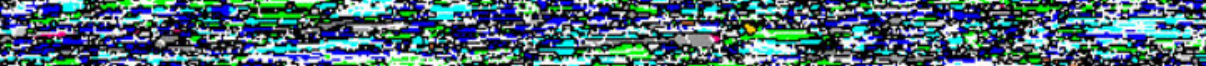
ar, 3. W.

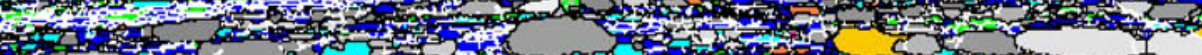

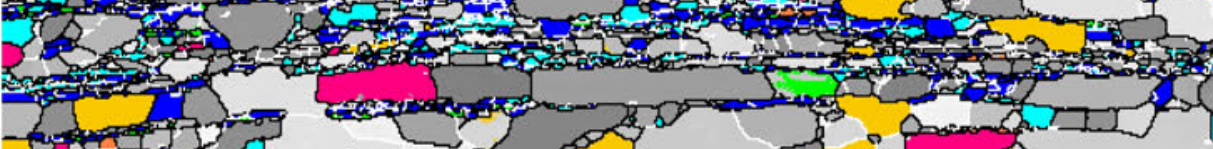
-

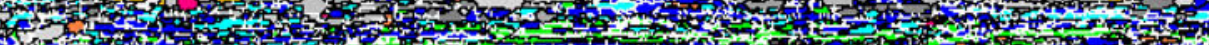

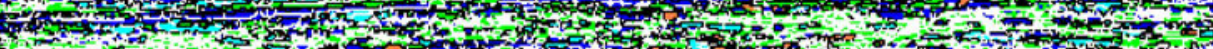

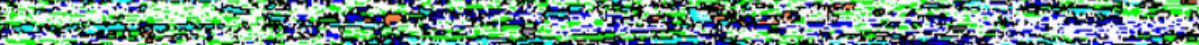

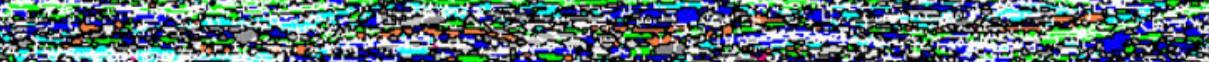

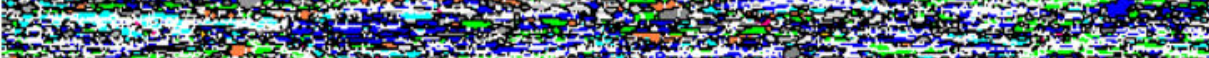

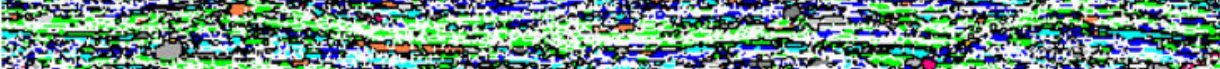
M. 


\section{(a)}

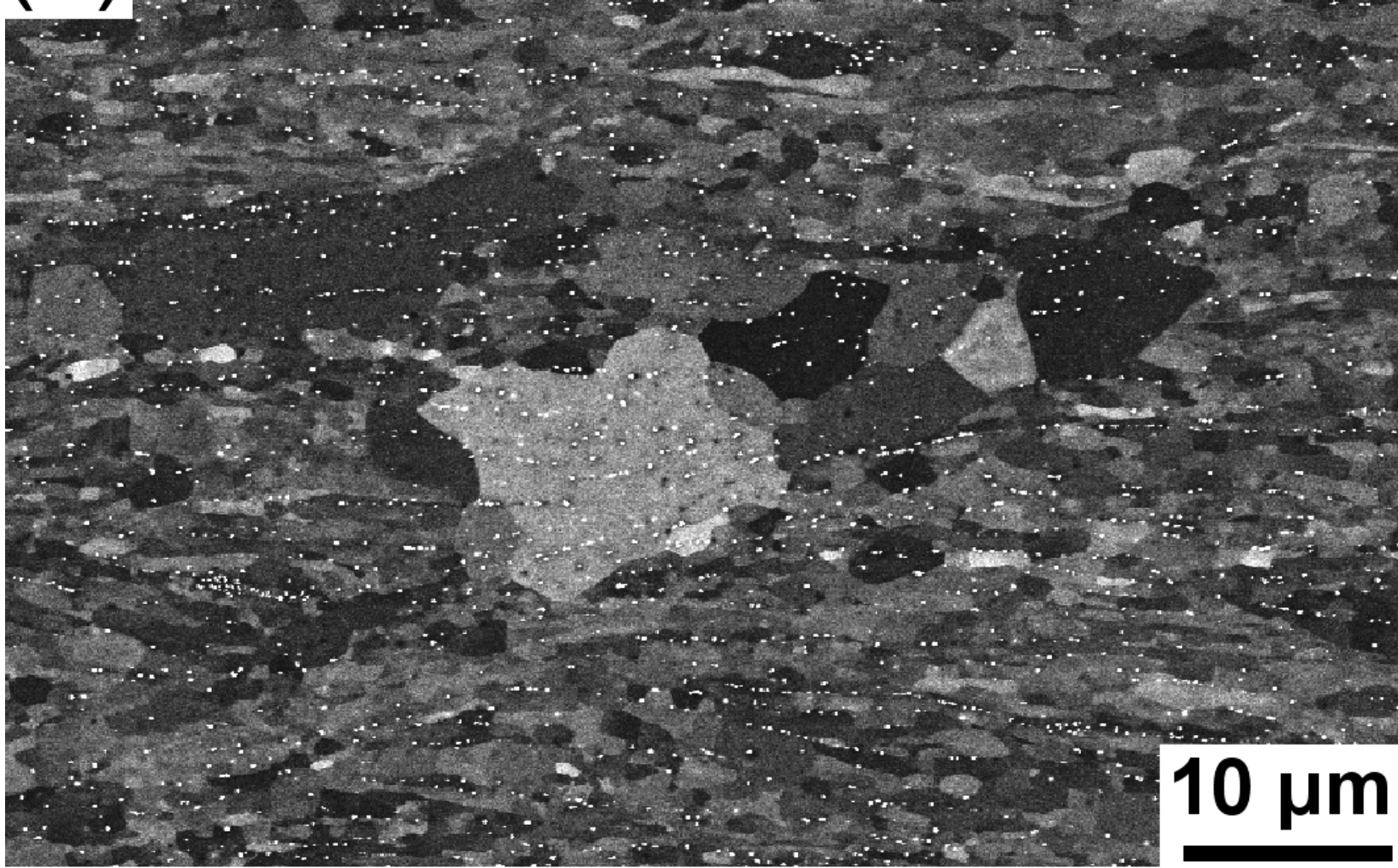

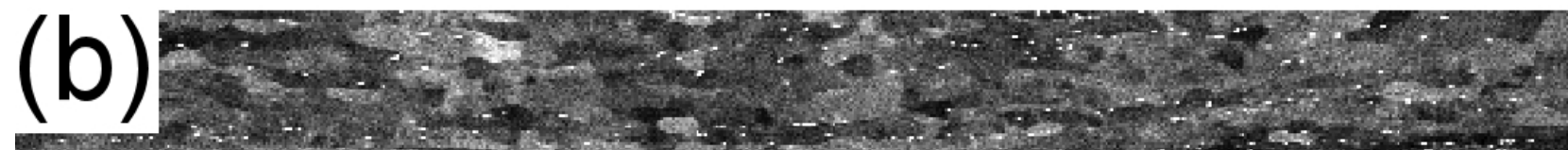

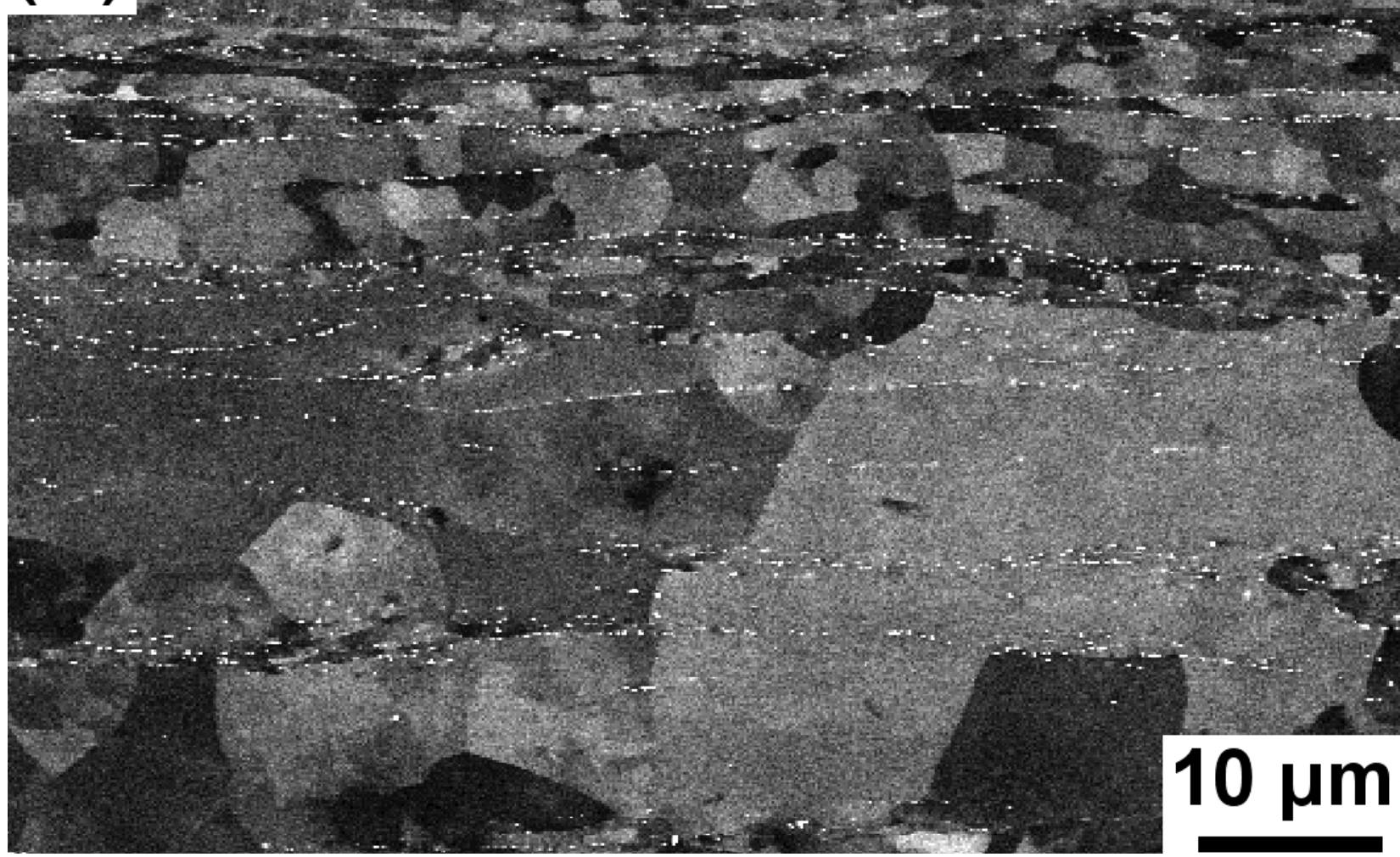


(a)

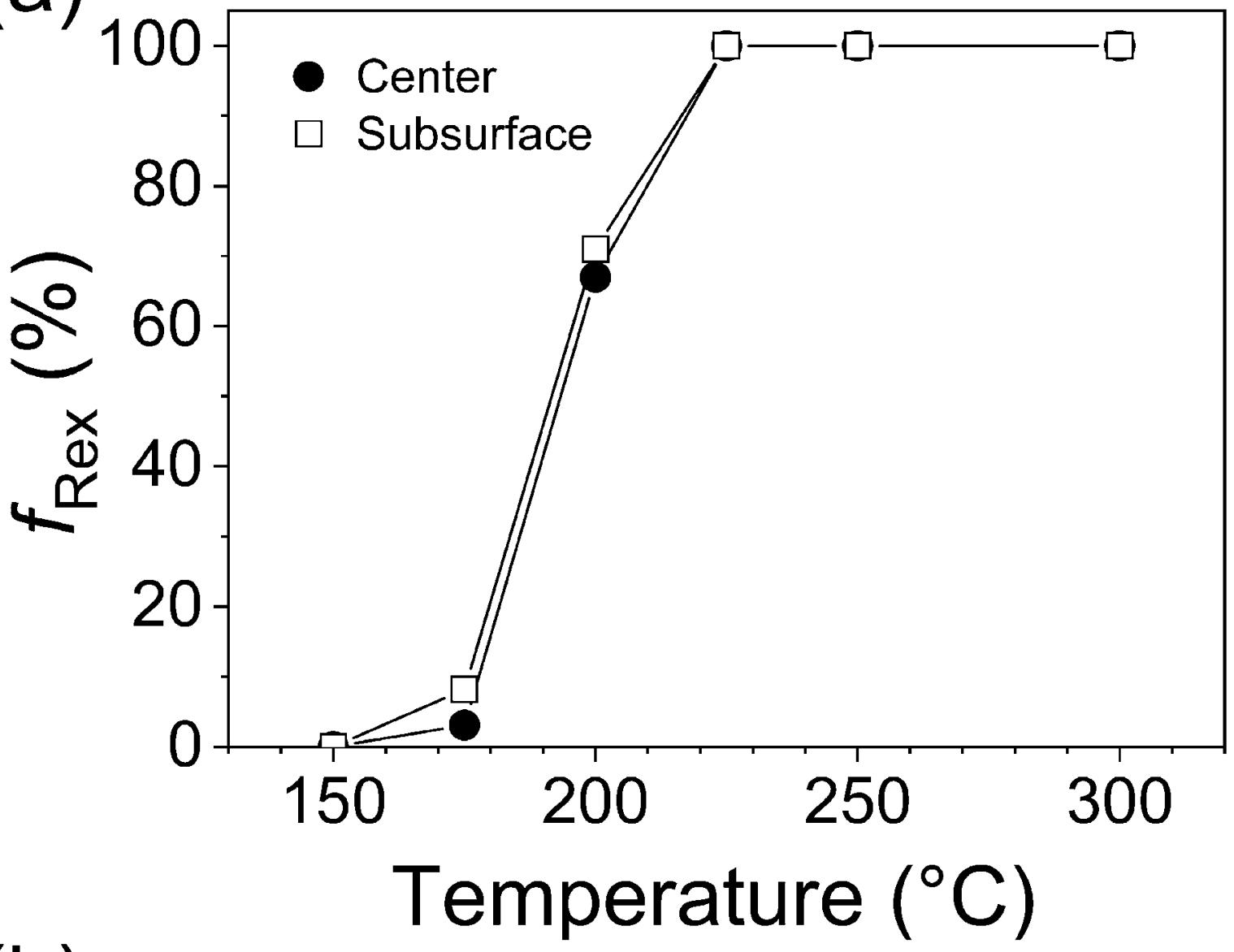

(b) 70

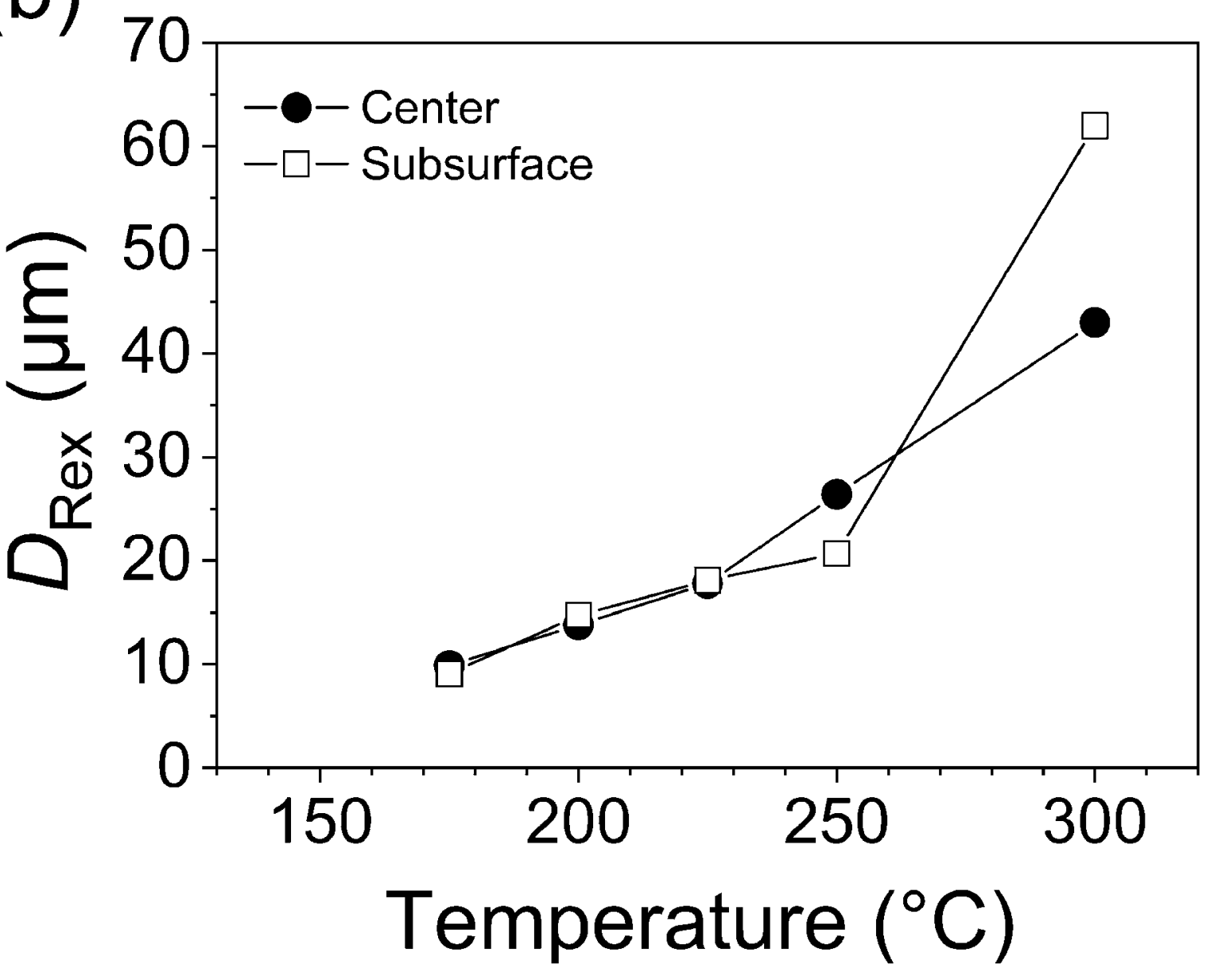




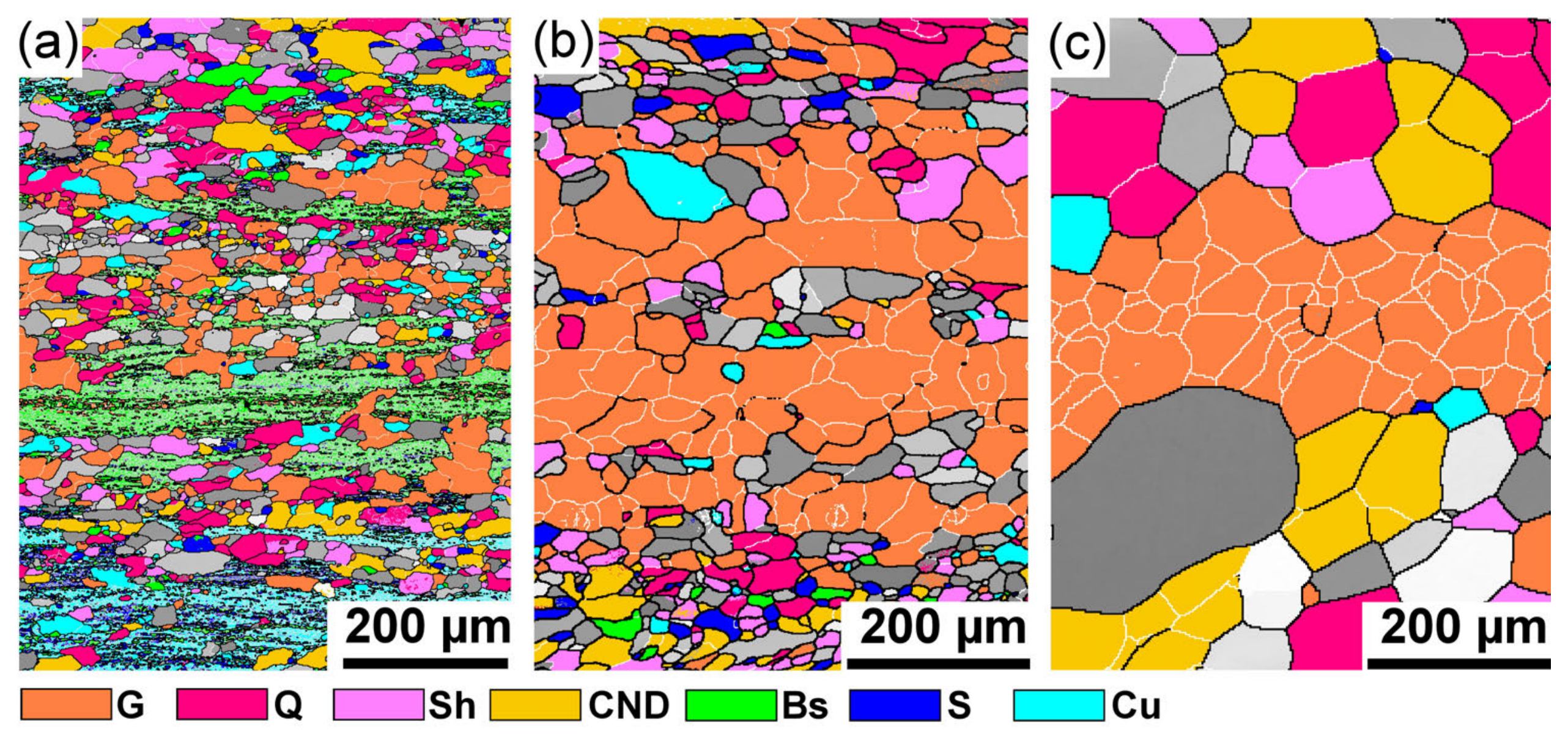



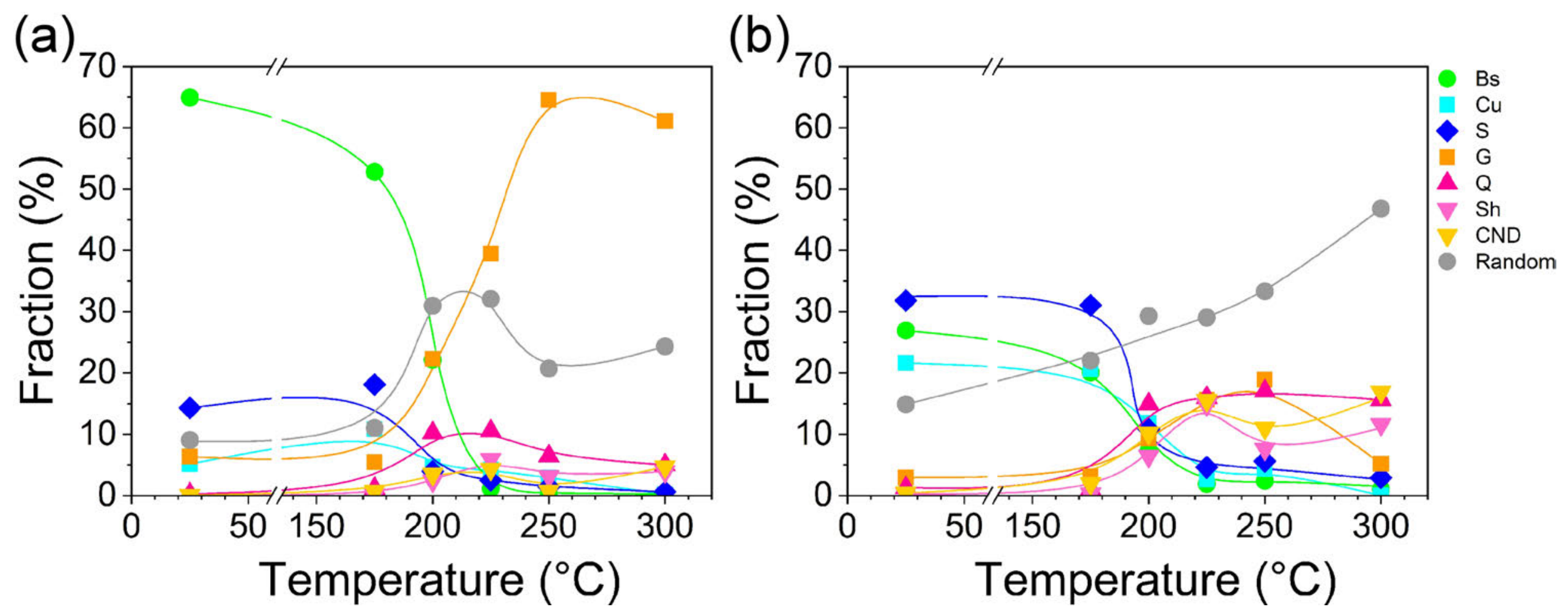


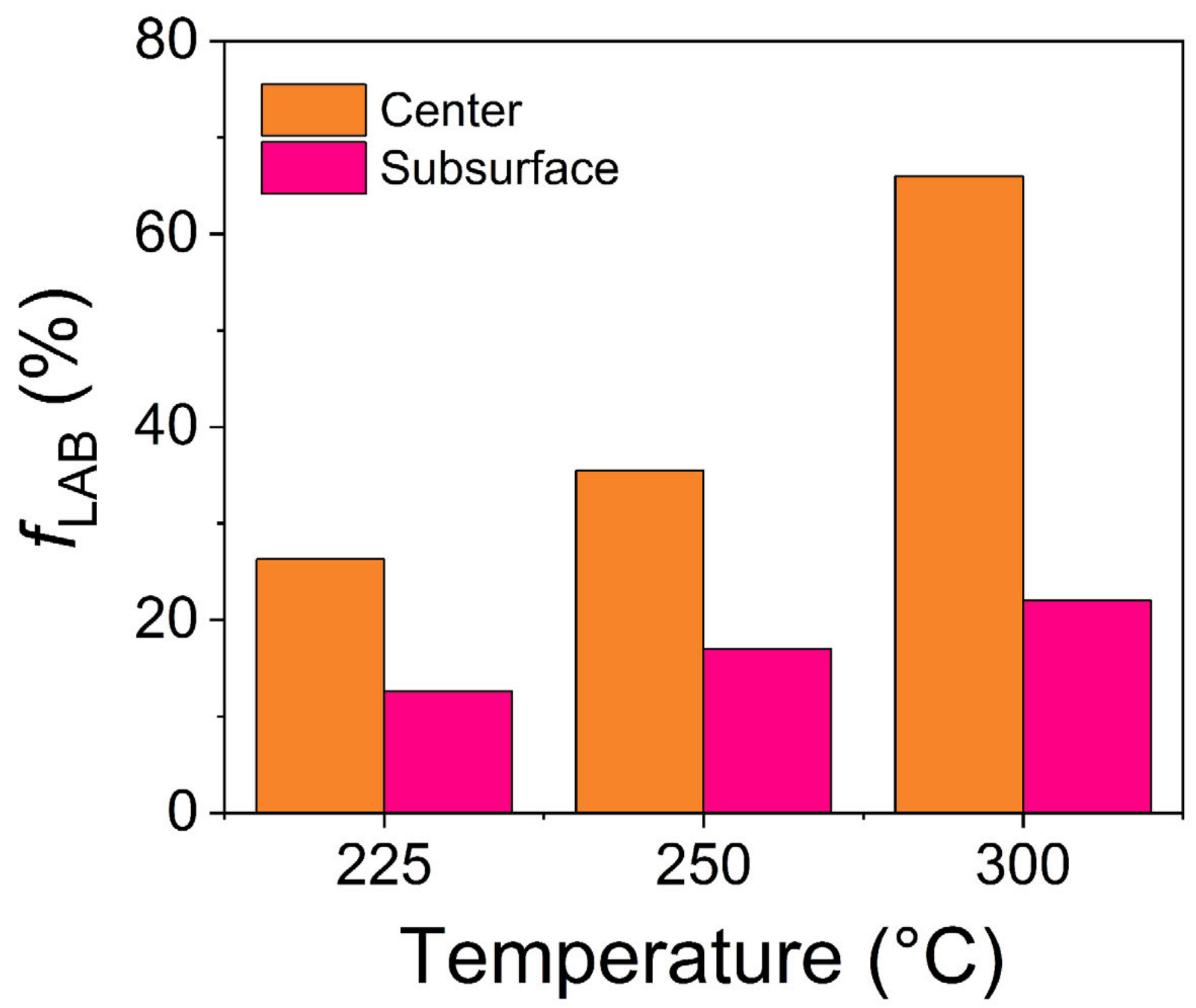

